\title{
Distance learning during coronavirus: problems and solutions
}

\author{
Olga Yarovaya $^{1,},{ }^{,}$Larisa Yarovaya $^{1}$, and Elena Bogatskaya $^{1}$ \\ ${ }^{1}$ Don State Technical University, 344003, Gagarina square 1, Rostov-on-Don, Russia
}

\begin{abstract}
This article concerns distance learning in modern conditions, its principles of operation, advantages and disadvantages, problems of students learning remotely, and also tells about our own experience of overcoming problems associated with the distance learning organization. In this article the difference between external programs and distance learning is being given, with the following describing features of the process. The authors cover the issues of organizing a proper distance learning process and analyze the experience of telecommuting and problems revealed by coronavirus restrictions. Results of the research suggest the structure of distant courses and discussion of distance learning strengths and weaknesses that teachers all around Russia faced to. Also attention is paid to analyses of the best suitable tasks that perform all goals of educational process and the problems that were discovered are being suggested solutions and ways to eliminate them.
\end{abstract}

\section{Introduction}

According to the order of the Ministry of science and higher education, Russian universities have switched to distance learning to avoid the spread of the coronavirus. Universities of the country were to organize distance learning for students to prevent coronavirus communication starting from March 16.

In such circumstances, all universities in the country should have implemented the full range of educational programs and developed a mechanism for providing students with individual vacations if necessary, as well as organize interaction between students and teachers via the Internet.

The temporary transition to distance learning is primarily a precautionary measure that implied not to allow ill people to infect others. The death rate from coronavirus is difficult to calculate and predict, since it is impossible to track the level of infection in humans. Country-by-country data suggested that about $3.4 \%$ of all coronavirus cases are fatal. Therefore, social distancing including distance learning can potentially save hundreds of thousands of lives. It is known that the elderly, those with weakened immune systems, or those with existing chronic diseases are particularly at risk. The form of distance learning as a form of social distancing was to not only to prevent students from getting sick, but also to save lives of teachers and society as a whole.

\footnotetext{
*Corresponding author: yarovaya.olya@gmail.com
} 
However, in some ways, this situation is good for the educational process because it gives the chance to think outside the box and get more modern and critical, since the direct process of transferring knowledge from a teacher to a student is disrupted due to distance and the inability to track the student's reaction. Of course, as soon as the dangerous period of the epidemic is over, all Russian universities will resume classes in the usual mode, but this is still an occasion to introduce new methods to the learning process.

The distance education has been discussed many times, and its pros and cons have been considered frequently and in detail. But technology does not stand still, and if some time ago online education seemed something complex and difficult to implement, now it is much easier to organize thanks to the Internet. Besides, there is no way to deny the relevance of this topic in modern conditions, so in this article we will consider both the theory and practice of distance learning. In particular we will present best practices based on our own experience during the epidemic.

Beforehand we are going to talk about distance learning as a concept. This process supposes that students are taught without personal meetings by using electronic means that provide instant communication among the teachers and those who study. Some authors like A. M. Bershadsky, I. G. Krevsky describe distance learning as a type of extramural studies, since distance learning includes elements of this kind of studies. For example, this is sending tasks for performing them after the class, as well as the fact that additional information services may be charged for providing extra information services. They do not distinguish between the concepts of training and self-education. Moreover, often video recordings, CDs, educational broadcasting, and radio are also called distance learning. Sometimes even learning with the help of a textbook, a book is also considered to be a remote process, since the author is at a distance and does not communicate with the student. The main argument against this opinion is that distance learning provides systematic and effective interactivity, thus becoming a full time and fully-featured education.

We consider distance learning as a new form of learning. Still it cannot be discussed without connection to the traditional one and cannot exist as a completely autonomous system. Distance learning is based on the same goals as face-to-face learning and is to transfer the same materials and content, but with a different form of presentation of the material. Still the form of presentation of the material, the form of interaction between teachers and students and students will be different, too. Didactic principles of distance learning organization (principles of scientific, systematic and systematic, activity, principles of developing learning, visibility, differentiation and individualization of learning, etc.) should also be the same, but they are implemented in specific ways, affected by the possibilities of the Internet information environment, and its services.

Thus, on the one hand, distance learning should be considered as a part of the general educational system, especially as a type of continuing education. On the other hand, it is necessary to distinguish between distance learning as a system and as a process. It means that teachers should provide and theoretically comprehend the stage of pedagogical design of this activity, its content and pedagogical components like they do in other kinds of educational systems.

Tasks of preparation and pedagogical design include creating e-courses, e-textbooks, training tools, and developing pedagogical technologies for organizing the learning process in networks. That is why a certain stage of preparatory work is required, which provides for a period of theoretical understanding of a new form of education and training. Developing distance learning courses is a more time-consuming task, even than creating a new textbook or textbook, since it is necessary to study in detail the actions of teachers and students in the new information and subject environment and eliminate chances that could cause misunderstanding for both teachers and students. 
The learning process involves usage of some prepared systems that are to provide materials and exchange information among the participants. And that is the thing that we would like to draw attention to in this article.

\section{Goals and Methods}

The "Concept of creation and development of distance learning in the Russian Federation" provides the following definition for distance education which is a set of educational services provided to the population in the country and abroad through a specialized information educational environment based on the means of exchanging educational information at a distance (satellite TV, radio, computer communication, etc.). Distance education is a form of continuing education, which is designed to realize human rights to education and information.

Therefore, talking about distance learning, we mean involving a teacher and students in this process, their communication with each other, the availability of necessary teaching AIDS and learning tools.

If the course is really intended to teach the students, e.g. for the interaction between the teacher and the student, the requirements for the organization of such a course, the principles of selection and organization, and the structuring of the material will be determined by the specifics of this interaction. Thus it seems to be obvious that courses for self-education are to be developed and structured differently compared to the one that would be used for online classes.

It considers both general didactic principles of the educational courses and requirements that are supposed to be maintained; and psychological features of perception of information from the screen and on a printed basis (because any text can be displayed with printer on paper), and ergonomic requirements. Also it should be taken into account that online education suggest new opportunities connected with software tools telecommunications networks and modern information technologies and it would have been a mistake not to use them up to maximized degree.

The exact subject that is needed to teach determines the goals and direction of course development. Thus, foreign language teaching implies such things for both students and teachers:

- teaching the first foreign language to students;

- reading at different levels of learning;

- speaking;

- writing tasks;

- listening exercises;

- grammar checking;

- vocabulary checking;

- phonetics practicing;

- practicing a foreign language at business level, dialects, slang and, language of scientific conferences;

- teaching cultural aspects of the foreign language being studied (on various aspects of country studies, speech etiquette, cultural heritage and history, etc.).

Alongside with goals of teaching, there are many methods that can be used while participating on the process of distance learning. The aim of this article is to research these methods and sum up the opinions of both groups involved in the process of distance learning - teachers and students.

\section{Results}


While using distance learning, we faced with the fact that a problem of differentiation becomes much more relevant than in the process of full-time training. The reason for this is that students united on one group may have drastically different level of knowledge, that is why each such course should begin with an introduction to the students, whoever they are. It should be followed by a test to determine the level of students, thus getting the full image of the group's knowledge and readiness for classes and their ability to understand new materials. Taking into account the results of testing, the teacher builds all the training tactics for the group. That is why we made such a list of features of distance learning:

Flexibility. Students in the distance education system have the opportunity to work at a convenient time, where they want and when they want. Students spend as much time on their studies as they need to master a particular discipline in the course they need;

Modularity. The course that the student takes gives a holistic view of a particular subject area. The schedule has been created for the course. The work program is divided into modules, the course structure is clear and understandable;

Quality control of training. Distance learning uses remote-organized exams in the form of tests, oral interviews, practical work, term papers, etc. The control system is systematic and is based on both operational feedback (provided with prompt access to the teacher or course consultant at any time convenient for the student) and deferred control (for example, during testing);

Specialized technologies and training tools. This is a variety of methods, forms and means by which the teacher interacts with students in the process of independent, but controlled development of a certain amount of knowledge. Various methods can be recommended for this purpose, such as demonstration, illustration, explanation, story, conversation, exercise, problem solving, memorizing educational material, writing, and repetition.

According to all these features, we suggest preparing and developing the following parts of the distance learning course:

1. General information about the course, its purpose, goals, objectives, content (structure). This information should be provided on the server for review, so that every participant can have a chance to get acquainted with it, thus getting the full image what they would study. The courses themselves are often open, but only registration gives a participant the right to get their own password, their own web page on the server and become a full participant in the training process under the guidance of a teacher.

2. Reference materials (in the form of databases) on the subject area of the course.

3. Blocks of tests (in a separate file) that allow teachers or admins to establish contact with users, get the necessary information and evaluate the progress of the students.

4. The actual training course (electronic textbook). Sometimes it is possible to make a list of materials (structured theory) with exercises. In our opinion, students should have an access to the theoretical part at any time when they need it. The problem of lacking this access we will discuss a bit later.

5. Block of tasks aimed at mastering the material and checking, controlling its understanding and comprehension.

6. Block of creative tasks aimed at independent application of acquired knowledge, skills, and skills in solving specific problems; implementation of projects individually, in groups of cooperation; practical work (individual, joint). We have already mentioned that students may have different levels of background knowledge, that is why they should have a chance either to deepen their knowledge by performing such projects or to get some more points for these tasks to improve their final mark.

7. Block for monitoring the success of independent activities of students, monitoring the results of their work (individually or jointly, in groups of cooperation).

As you can see, we think that any distance learning course is a full learning process. 
For distance learning the teacher must use more than just the Internet. Based on practice, we believe that the optimal ratio of all forms and means for distance learning should be presented as follows:

\section{The optimal ratio}

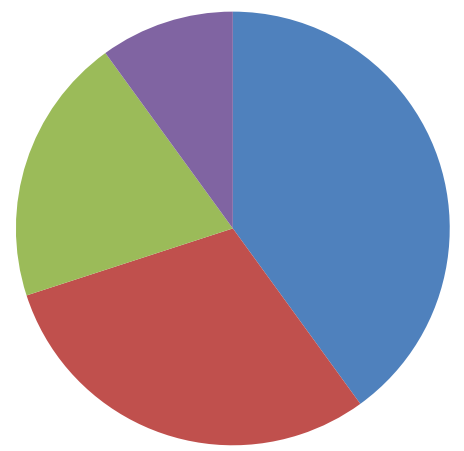

printed tutorials

- training materials on various platforms for example, Moodle, SKIF

$\square$ video conferencing classes

" other training tools

Fig. 1. The optimal ratio of all forms and means for distance learning

However, we do not deny the fact that modern students often prefer to work with electronic versions of textbooks and manuals, which from the point of view of the teacher of the "old school" seems inconvenient and even harmful because the student is deprived of the opportunity to make notes on the paper, which has to be paid attention to in traditional training.

If earlier distance learning was associated with rare meetings of students with a teacher who gives them a written task, also known as "test papers", now there are many tools that facilitate the process of distance education for teachers and students, translating it into an online format.

The most popular tools that teachers use in their classes during the epidemic are Zoom, Skype, and Discord. These are programs for organizing online video conferences that offer most of their main functions for free. With this type of distance learning, students can connect to teachers' lessons live, ask and answer questions in real time, demonstrate their best practices, and show presentations, videos, slides, recordings, and have the ability to listen to audio tracks. Distance education is often a mix of different tools and tactics to maximize their use in teaching students. The effectiveness of distance learning depends on the quality of the materials used (training courses) and the skill of the teachers involved in this process. Moreover, one of the platforms for conducting online lessons is Discord, which is even more convenient than Skype and other programs. This program is especially popular among students and the developers provide many new features to satisfy all needs.

It is all just big talk as when it comes to practice, students and teachers may have certain problems in the process of switching to distance learning. Usually students feel great in the online learning environment, easily attend various additional courses and study them remotely. Our own experience shows that in general students can easily cope with distance learning. But there are groups of students who may face great difficulties in this form of training.

For example, students with physical disabilities may find it difficult to use distance learning software. Moreover, some students due to their physical abilities may not be able to participate in this type of training at all. Given that success in distance learning largely depends on computer skills, Internet usage, and the ability to cope with occasional technical 
difficulties, most students have no problems registering on various platforms. They can easily set up the necessary equipment such as microphones, audio playback devices, Webcams, and use training platforms that are often quick and has an intuitive interface. But there are always categories of students who do not have such skills or try to pretend to be such so that trying to ease their own workload. Therefore, it is important to select the most simple and undemanding programs that will not be difficult to use.

In addition, an important aspect is the choice of a platform, preferably one, in order to avoid distraction of students' attention when switching from one to another application, since all of the above platforms provide all the necessary functions.

The thing is that teachers should not forget the possible congestion of networks and platforms that are used for the educational process. During self-isolation many people use the Internet, which can lead to decrease in connection speed. For example, governments recommend reducing the bitrate of video clips. Thus, they reduced the quality on the popular video hosting sites such as YouTube or Netflix. When talking about Russian experience, we should not forget about the suggestion made by the Ministry of communications of the Russian Federation in which they asked local Internet service providers to limit the maximum quality of video content playback. All this is done in order to reduce the burden on the server side and the communication networks. But despite the measures taken, it is also important to take this into account when establishing communication with students. In addition, the number of platforms that allow you to contact students and organize online training is not so high, which also affects the quality of communication during the class. So students and teachers should take into account that there is always a risk of "losing" a number of students during the class. Often there are breaks and crashing of the platforms which is worth remembering and having another way to communicate with students.

An important problem may be the lack of students' technical equipment, which we have already mentioned earlier. In rural areas where a lot of students live access to the Internet is sometimes low. Students who do not have permanent access to Wi-Fi or a computer may find themselves at an extreme disadvantage compared to other students and will be completely deprived of the opportunity to study remotely.

The next difficulty is that a number of practical classes involve the teacher's and the student's having expensive equipment. In this case we can observe that modern existing educational and methodological complexes of disciplines are not suitable for distance education courses.

Thus, a narrowing of the audience of students is happening, which may adversely affect the performance of some students. The difficulty of the teacher's work at this moment is to find a way to each student, to create conditions for working with them, showing an individual approach.

There are other groups of problem students, but this cause is based on personal characteristics. So, some students need a close connection with the teacher. Students want to see the teacher and communicate with them personally and face to face. A number of students often turn into passive listeners due to the lack of control on the part of the teacher. However, this problem also exists in traditional training.

Despite all the problems and shortcomings of the distance learning system, the demand for this format is growing every year. The conducted research on the issue of distance learning allows us to draw a conclusion about the feasibility and effectiveness of using distance learning in various emergency situations. There is an increasing need for distance learning for students during epidemics, natural disasters, when it is impossible or dangerous to attend the university. In case of force majeure, distance learning is a necessary process, and at the same time, it is a new form of education, along with full-time and part-time. 
When switching to distance education, we went through all the above problems. Some have been successfully resolved, and some still require further study and overcoming. For example, the technical problem of video conference program hang-up was solved simply and elegantly by turning off the video broadcast, which allowed many students to stop suffering from program hang-ups and lack of synchronization of audio and video sequences.

It is very important to keep in touch with students, who can always suggest ways to solve problems, suggest new platforms and actions. So, we discovered that to test students' knowledge, it is possible to use various programs to create tests, for example, Google form or Kahoot! Unfortunately, it is difficult to notice common problems when interviewing a vocabulary learned by heart orally, while it is much easier to understand when analysing the answers to the test, which can later make it easier to work on errors.

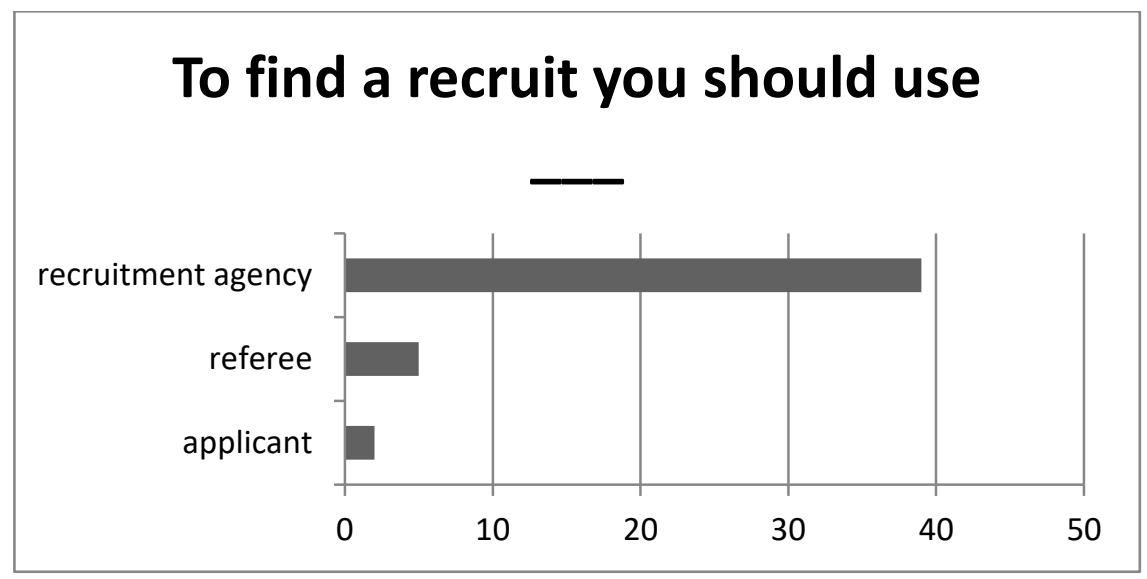

Fig. 2. Example of test analyses

However, for these purposes there were difficulties, as always in the process of creating new content: when composing a question with an open answer, instead of 5 given options, students usually typed the sixth or seventh, which had to be added to the options with the points after being scored to the final mark. Often these mistakes were quite annoying and consisted only in the search, but not errors, in fact.

Travis works in a sports shop and gets a basic pay of $£ 4.50$ per hour.lf he worked 35 hours last week, how much was he paid ? *

Fig. 3. Example of the exercise with open questions 


\section{Discussion}

Feedback from students helps you find mistakes and better adapt to the changed learning environment in this situation. To understand how successful the introduction of the new system was, we conducted surveys among students.

So, after the first week of distance learning, less than half of the students were satisfied with this format of training: $29 \%$ and $71 \%$, respectively. In the future, the indicators of satisfaction with the educational process began to grow, up to $72 \%$ and $28 \%$ in proportion.

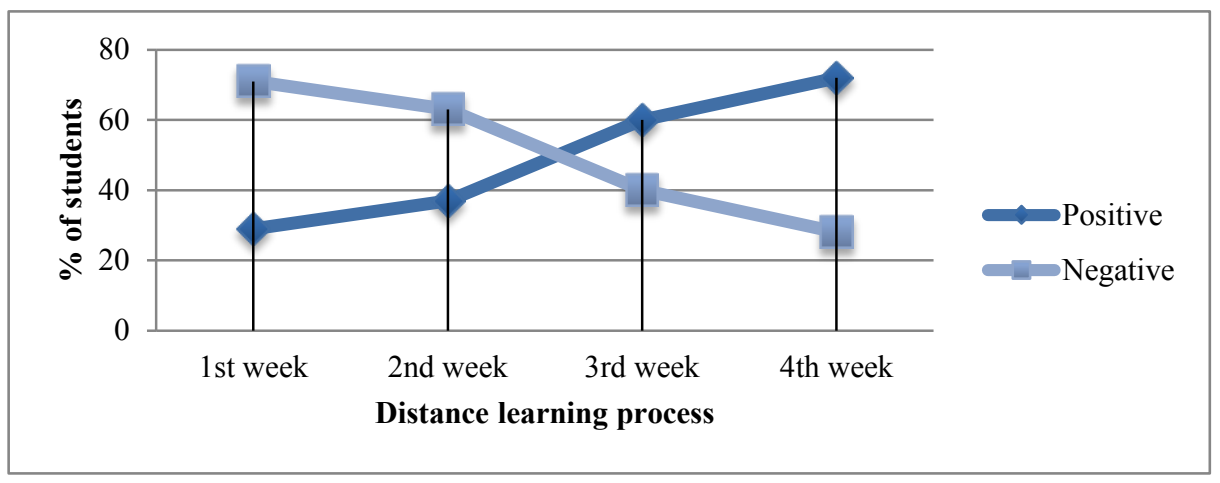

Fig. 4. Indicators of satisfaction with distance learning

When asked about the positive characteristics of this type of training, students pointed quite trivial things:

- ability to learn from the comfort of your home;

- no skipping classes without leaving home;

- no class absence due to illness;

- easy access to the whole content;

- difficulty of being late for a couple;

- no need to get up early;

- cozy, homely atmosphere, no tension;

- ability to type, rather than hand-write homework.

The disadvantages of distance learning students included:

- a large amount of independent work;

- difficulties with understanding the material;

- lack of contact with the teacher and the group;

- the need to spend a lot of time in front of the monitor;

- problems with the equipment.

We have already discussed the technical problems above, so we will not return to them. As for the difficulties with understanding the material, this problem was surprisingly often mentioned by specific students, along with a large amount of independent work and homework. While the rest of the students did not have these problems. It is not surprising but quite sad that many students find it quite difficult to organize themselves to study even during traditional training,

However, we should not forget that with the change of the training format, the wording has to be also changed and varied. Unfortunately, the usual communication in the classroom is not very similar to how training takes place in a remote format. Even if classes are held online, this does not exclude the fact that some questions will remain unsanctified, so it is important to try to reduce their number in advance, carefully preparing a package of tasks beforehand. For example, the usual lecture notes, notes, will no longer take place, thus later the student may have difficulty while remembering what was given and discussed in 
the classroom. Therefore, it is important to structure the lesson, to announce the topic and key questions at the beginning of the class, at the end asking students to recall what they have learned and give them the chance to summarize the material.

Proper organization of remote work often allows you to avoid difficulties with understanding the material by students, as well as reduce the number of independent study of some issues in addition. So, the important step is not to forget what is needed to add detailed instructions about the execution process to the training materials. It is even advisable to use the same constructions and explain them in the same words as you would do in the classroom:

\section{Part 1. Telephone Vocabulary}

Here are many of the words and terms we use to talk about telephones and using them. With example sentences and special meanings related to landline phones, mobile phones and smartphones.

Read and learn the words here.

\section{Conclusions}

Summing up, we urge you to remember the fact that the purpose of any training is to teach something new, and the remote format of knowledge transfer is no exception, perhaps unusual, but quite convenient. Therefore, the teacher has to devote a lot of time to creating material for independent work of students.

Also, teachers should not forget that distance learning increases the temptation to use dishonest formats of passing the control, for example, students can always place a cheat sheet on the display or just search the Internet for the answer to a question, so the tasks should not be too easy to get an answer or after visiting the first site in Google. To perform this task, teachers will have to think a lot about the quality of tasks and their format.

Besides, ill-considered tasks result in a rather unexpected but typical mistake, which, in our experience, can take a short-sighted teacher much more time than a well-thought-out task. This error is to ask students to perform tasks and to send an e-mail later getting a large number of e-letter, all of which are to be checked and provided with the feedback. In our opinion, this can only be done in the case of special students who are unable to complete the task and that is why they need your feedback.

Thus, the coronavirus epidemic has revealed a real problem in fact rather than in word which is the lack of readiness for the transition of many students to distance learning, and the inequality in access to Internet resources of students who live in cities and villages. Nevertheless, this situation has shown us how important it is for everyone to be flexible today, how important it is to be able to adapt to different realities of life today.

\section{References}

1. T. Anderson, J. Dron, The International Review of Research in Open and Distance Learning, 12(3), 80-97 (2010)

2. T. Anderson, J. Dron, The International Review of Research in Open and Distance Learning, 12(3), 80-97 (2011) doi:10.19173/irrodl.v12i3.890.

3. A. M. Kaplan, M. Haenlein, 59(4), 441-50 (2016) doi:10.1016/j.bushor.2016.03.008

4. T. Nguyen, MERLOT Journal of Online Learning and Teaching, 11(2), 309-319 (2012)

5. P. Olszewski-Kubilius, S. Corwith, Gifted Child Today, 34(3), 16-24 (2011)

6. A. Murphy, R. Crosser, Strategic Finance, 91(9), 19-20 (2010) 
7. K. J. Perdue, T. Valentine, The American Journal of Distance Education, 12(3), 29-41 (2018)

8. C. J. Popovich, R. E. Neel, The American Journal of Distance Education, 19(4), 229240 (2015)

9. F. A. Kultuk, M.Gulmez, Procedia - Social and Behavioral Sciences, 46, 2733-2737 (2012) doi: https://doi.org/10.1016/j.sbspro.2012.05.556

10. A. Fidalgo, O. Thormann, A. Kulyk, J. A. Lencastre, International Journal of Educational Technology in Higher Education, 17, 18 (2020) doi: https://doi.org/10.1186/s41239-020-00194-2

11. R. Bradley, B. Browne, H. Kelley, College Student Journal, 51(4), 518-530 (2017)

12. D. L. Carver, Jr. Kosloski, M. F. Quarterly, Review of Distance Education, 16(4), 7-21 (2015)

13. I. P. E. Costa, H. d. C. Faria, A. S. Neto, Gazeta Médica, 5(4), (2018) doi: 10.29315/gm.v5i4.214

14. P. L. De, C. $\quad$ D. K. Zhu, 33(1), 18-33 (2018) https://doi.org/10.1080/02680513.2017.1414586.

15. R. Dobbs, A. del Carmen, C. Waid-Lindberg, Quarterly Review of Distance Education, 18(1), 98-109 (2017) doi: https://eric.ed.gov/?id=EJ864039.

16. V. Gonçalves, I. Chumbo, E. Torres, B. Gonçalves, In ICERI2016 Proceedings, 83508358 doi: https://doi.org/10.21125/iceri.2016.090.

17. H. Hashim, Z. Tasir, LATICE 2014, 267-271 (2014) doi: https://doi.org/10.1109/LaTiCE.2014.58.

18. S. C. Kurt, B. Yildirim, Theory \& Practice, 18(2), 427-446 (2018) doi: https://eric.ed.gov/?id=EJ1201838.

19. S. A. Lei, R. K. Gupta, Education, 130(4), 616-631 (2010) doi: https://www.questia.com/library/journal/1G1-227597132/college-distance-educationcourses-evaluating-benefits.

20. V. P. Mahlangu, In M. Sinecen (Ed.), Trends in E-learning (2018) doi: https://doi.org/10.5772/intechopen.75702.

21. M. Nakamura, Quarterly Review of Distance Education, 18(3), 75-87 (2017) 